\title{
Portable broadband seismic network in Vietnam for investigating tectonic deformation, the Earth's interior, and early-warning systems for earthquakes and tsunamis
}

\author{
Bor-Shouh Huang ${ }^{\mathrm{a}, *}$, Tu Son Le ${ }^{\mathrm{b}}$, Chun-Chi Liu ${ }^{\mathrm{a}}$, Dinh Van Toan ${ }^{\mathrm{c}}$, Win-Gee Huang ${ }^{\mathrm{a}}$, Yih-Min Wu ${ }^{\mathrm{d}}$, \\ Yue-Gau Chen ${ }^{\mathrm{d}}$, Wen-Yen Chang ${ }^{\mathrm{e}}$ \\ ${ }^{a}$ Institute of Earth Sciences, Academia Sinica, P.O. Box 1-55, Nankang, Taipei 115, Taiwan \\ ${ }^{\mathrm{b}}$ Institute of Geophysics, Vietnamese Academy of Science and Technology, Hanoi, Viet Nam \\ ${ }^{\mathrm{c}}$ Institute of Geological Sciences, Vietnamese Academy of Science and Technology, Hanoi, Viet Nam \\ ${ }^{\mathrm{d}}$ Department of Geosciences, National Taiwan University, Taipei 106, Taiwan \\ e Department of Natural Sciences, National Science Council, Taipei 106, Taiwan
}

\section{A R T I C L E I N F O}

\section{Article history:}

Received 11 May 2008

Received in revised form 23 January 2009

Accepted 2 February 2009

\section{Keywords:}

Seismic monitoring

Broadband array

\begin{abstract}
A B S T R A C T
As part of a collaborative project involving researchers from the Vietnamese Academy of Science and Technology (Hanoi, Vietnam), National Taiwan University (Taipei, Taiwan), and Academia Sinica (Taipei, Taiwan), a 25-station broadband seismic array was installed in northern Vietnam during December of 2005 with the aim of acquiring a wide dynamic range of seismic data at a high spatial density. The stations were designed to image and interpret crustal and mantle structures beneath northern Vietnam, including information that would help to reconstruct the geodynamic evolution of the Red River Fault Zone. Since its deployment, the array has recorded significant local, regional, and teleseismic events. The high-quality distance and azimuth coverage of available events will help us to answer questions regarding the nature of deep seismic structures beneath the array and the regional tectonic evolution. As an unexpected bonus, the array recorded near-antipodal seismic waves from significant seismic events in South America, thereby providing valuable seismic data for analysis of the Earth's deep interior. A similar network is planned for South Vietnam in the near future with the aim of studying the deep structure of the South China Sea. The proposed stations are scheduled for upgrades to enable the real-time transmission of data for earthquake monitoring and tsunami warnings for the South China Sea.
\end{abstract}

(c) 2009 Elsevier Ltd. All rights reserved.

\section{Introduction}

Insights into the processes of continental collision and resultant geological effects have been obtained by studying the Himalayan mountain belt and surrounding regions (Tapponnier et al., 1986; Molnar et al., 1993). Crustal thickening in and around the Tibetan Plateau, and associated uplift, are the direct results of collision between the Indian and Asian continents (Fig. 1). Large-scale strikeslip movement along the Red River Fault (RRF) has been directly linked to this collision process, and is widely viewed as a key process in shaping the present-day geology of Southeast Asia and in initiating the opening of the South China Sea (SCS; Tapponnier et al., 1990; Lee and Lawver, 1995; Chung et al., 1997).

Knowledge of fault structure and deformation mechanisms in the deep Earth is central to our understanding of how the lithosphere behaves during continent-continent collision. Mantle dynamics and plate interactions in Southeast Asia have been

\footnotetext{
* Corresponding author. Tel.: +886 2 27839910x323; fax: +886 227839871 .

E-mail address: hwbs@earth.sinica.edu.tw (B.-S. Huang).
}

repeatedly examined based on geological and geochemical data (Chung et al., 1998); however, the relatively small number of geophysical surveys and seismic observations means that little is known of the present tectonic stress field and the nature of structures in the deep crust and upper mantle - features that provide a unique constraint on the geodynamic evolution of Southeast Asia.

Regional seismic arrays provide a powerful means of detailed mapping of deep-Earth structure and seismology, and remain the best tool available in this respect; however, spatial aliasing arising from the less-than-optimal distribution of global seismometers and sparseness of permanent regional seismic networks in Southeast Asia have long made it difficult to determine regional tectonic stresses and deep-Earth structure based on observations accumulated from studying regional earthquakes and teleseismic waves. The temporary deployment of portable broadband seismometers can help in this regard by providing a high-resolution window into the deep mantle.

More than 50 portable broadband seismic instruments are currently operated by the Institute of Earth Sciences at Academia Sinica (IESAS) as part of the Broadband Array in Taiwan for 


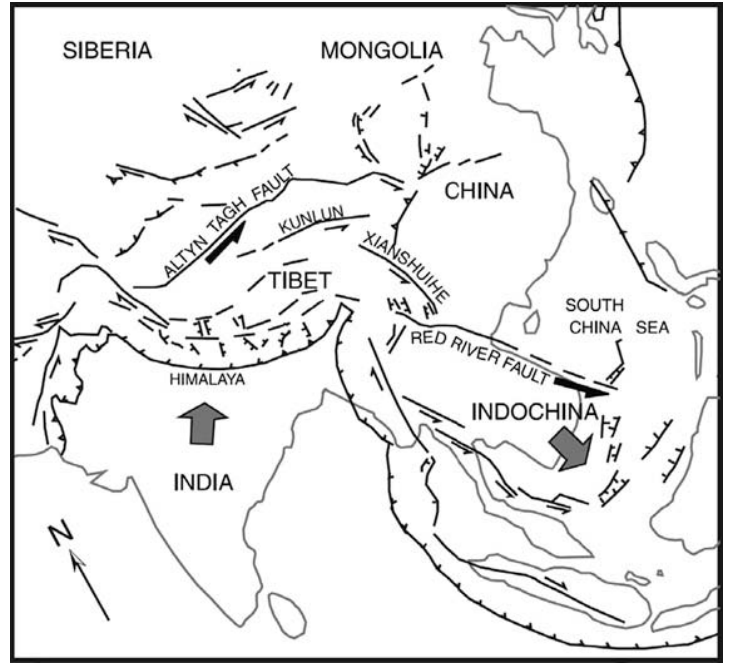

Fig. 1. Tectonic map of Asia, showing the major Cenozoic fault systems (after Tapponnier et al., 1990) and large-scale strike-slip movement along the Red River Fault accommodating the eastward extrusion of Indochina in response to northward penetration by India. Symbol of large gray arrow indicates plate motion direction. Other small arrows indicate relative block motions along faults.

Seismology (BATS; Kao et al., 1998). These instruments are deployed throughout Taiwan and surrounding islands to study the deep Earth interior and seismic hazards. The National Science Council of Taiwan (NSC) and IESAS have encouraged the deployment of these instruments abroad as part of international cooperation and to enlarge the scope of research.

As part of a collaboration involving researchers from the Vietnamese Academy of Science and Technology (VAST), National Taiwan University (NTU), and Academia Sinica, a 25-station broadband seismic array was installed in northern Vietnam in the end 2005. The stations are distributed uniformly over northern Vietnam, and provide a high density of seismic data with a wide dynamic range that enables analysis of the tectonic evolution of the RRF. We hope to provide additional constraints on the style of crustal deformation and mantle evolution in this region by quantifying these observations, thereby improving our understanding of the relevant geological processes. The array also provides useful information in determining crustal and mantle structures for the purpose of regional earthquake monitoring and seismic hazard mitigation in this region, as well as for investigating the deep Earth interior using near-antipodal seismograms.

\section{Active faults and seismicity in Vietnam}

The RRF has previously been recognized as a large-scale left-lateral structure in support of the hypothesis of continental extrusion resulting from India-Asia collision (Tapponnier et al., 1986). The zone is widely regarded as the suture that separates South China from the Indochina block and as a lithospheric-scale strike-slip fault (Tapponnier et al., 1990; Lee and Lawver, 1995; Leloup et al., 1995). Allowing for eastward extrusion of South China, the continued deformation of Asia eventually resulted in reactivation of the RRF in a right-lateral sense. The opening of the SCS is

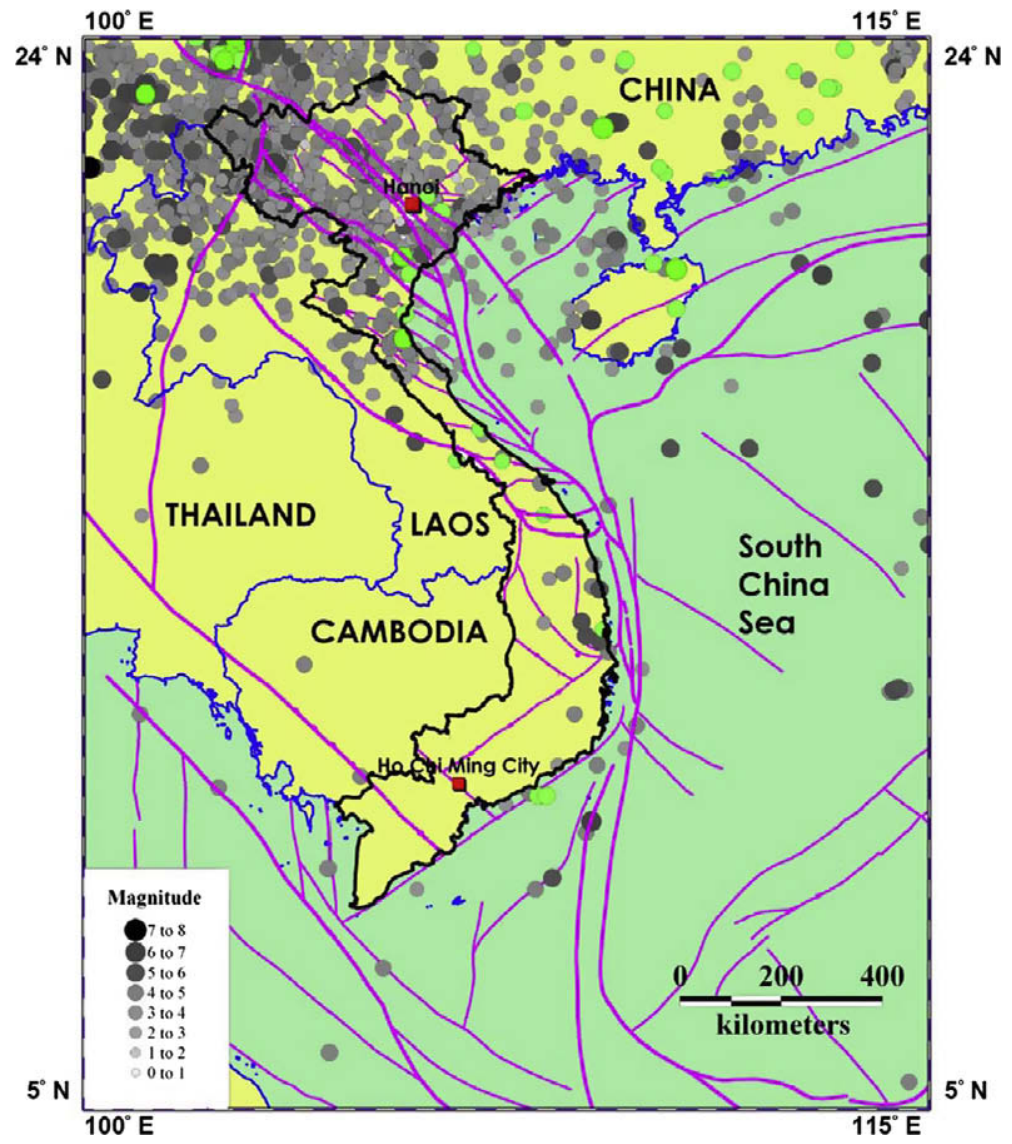

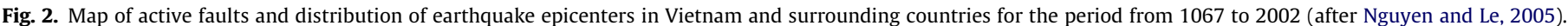

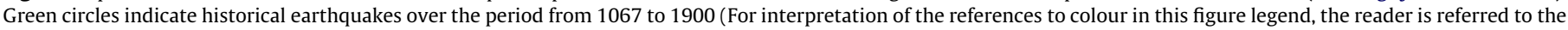
web version of this article.). 
interpreted as pull-apart deformation of the southeastern termination of the RRF (Fig. 1).

Based on the nature of the contact between the old pre-Cenozoic block on the Indochina Peninsula and the South China block, the RRF is divided into two parts. The north segment of the RRF located in China region and the south segment crosses northern Vietnam. The two segments record contrasting seismic activity, with the north segment recording a higher level of earthquake activity. However, the south segment of the RRF dominates the tectonic evolution of the northern Vietnam region. As with the RRF, most of the main faults in northern Vietnam are strike-slip faults. The deep-level NW-SE-trending strike-slip fault system in North Vietnam is more active than its perpendicular NE-SW-trending fault system. According to the earthquake catalog compiled by the Institute of Geophysics (VAST), 90\% of earthquakes in Vietnam territory are located in northwest Vietnam (Fig. 2). Outside of this region, there are no reports of earthquakes with a magnitude above 5.5.

Vietnam is regarded as a low-seismicity region; however, it remains tectonically active, as indicated by the occurrence of moderate earthquakes in the country and adjacent areas. Such earthquakes have resulted in heavy damage, comparable with the damage reported from historical earthquakes (Fig. 2). Damaging seismic events occurred in northwest Vietnam near Dien Bien in November of 1935 and on 19 February 2001, and near Tuan Giao on 24 June 1983 (Nguyen and Le, 2005). These events resulted in the destruction of buildings and structures over areas of thousands of square kilometers. In addition, moderate earthquakes related to volcanic activity occur offshore from central Vietnam. Ongoing economic development means that increasing numbers of highrise buildings and large public facilities are being constructed in the main cities in Vietnam; consequently, seismic hazard analysis and mitigation will be of increasing importance in the near future, with the aim of design and risk evaluation.

\section{Deployment and data processing}

Deployment of the portable array began in December of 2005 . We installed a network of 15 broadband seismic instruments, also using seismic stations of the Vietnam seismic network located in northwest Vietnam (Fig. 3). Four of the instruments employed
Streckeisen STS-2 sensors: the others employed Nanometrics Trillium 40 broadband sensors. These seismometers measure ground motion over a wide frequency range with a flat response to velocity from at least $0.025-50 \mathrm{~Hz}$ (Trillium 40). The STS-2 seismometers have an extended lower limit to $0.008 \mathrm{~Hz}$. The output from the seismometers is recorded on a Quanterra/Kinemetrics Q330 recorder with 24-bit analogue-to-digital conversion. The ground-motion signal is recorded continuously and digitized at a rate of 100 samples per second, which allows the recording of nearly 6 months of continuous data on a 20-Gbyte high-capacity recording system (Quanterra PB14F Packet Baler). Time-keeping is provided by a built-in Global Positioning System (GPS) clock that resets the internal clock each hour to keep timing errors below 1 millisecond. Power is supplied by a $12-\mathrm{V}$ automotive battery recharged by AC power or solar panels. The network was extended to 25 stations in 2006, including several new stations located northeast of the Red River and one station located near Ho Chi Minh City in South Vietnam. Each of the new stations was equipped with a Quanterra Q330 digitizer, Kinemetrics Baler-14, and Nanometrics Trillium broadband seismometer. The array has a uniform distribution (inter-station spacing, about $100 \mathrm{~km}$ ) throughout northern Vietnam, covering the RRF and the region of high seismic activity in northwest Vietnam (Fig. 3).

Array data are routinely retrieved by VAST and IESAS staff. Once the seismic data are collected from field stations, they are copied to backup devices and data segments are extracted for those events that satisfy a simple magnitude-distance criterion. The network not only records local earthquakes, but also significant regional and teleseismic events. During the operation period, the level of seismic activity in the surrounding region was high, and a large number of earthquakes were recorded. The extracted waveform data are converted to Seismic Analysis Code (SAC) format and archived as an event database for future analysis. Local events are selected using the earthquake catalog compiled by the Vietnam Seismic Network operated by the Institute of Geophysics, VAST. We relocated 137 local events from array data for the first 2 years of observations (December 2005-November 2007). Most of the events occurred on the western and northern borders of the array (Fig. 4). Events were also selected using the preliminary Determination of Epicenters (PDE) published by the US Geological Survey.

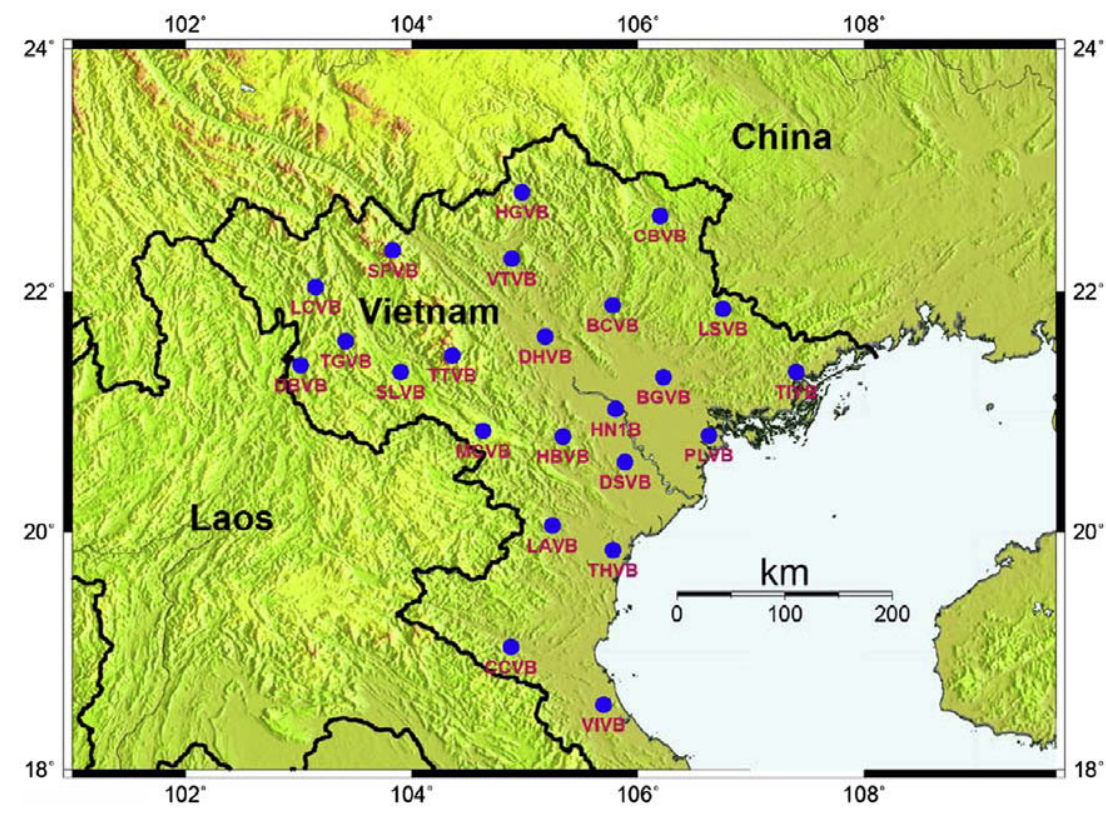

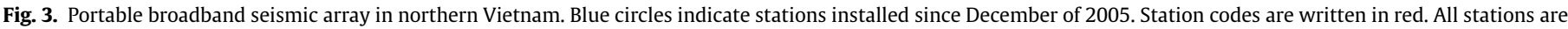
currently operating (For interpretation of the references to colour in this figure legend, the reader is referred to the web version of this article.) 


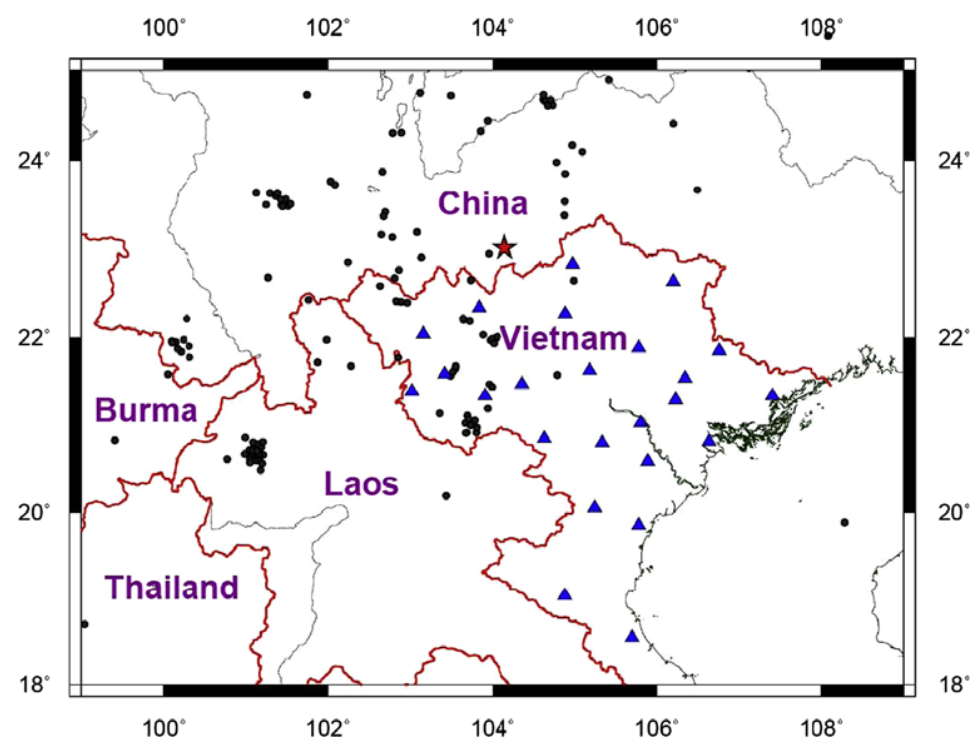

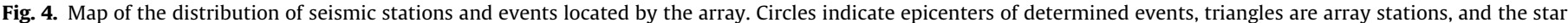
represents the epicenter of the earthquake discussed in the text as an example.

The regional and teleseismic events recorded by the network are shown in Fig. 5, which shows the locations of all events for which data were extracted from the continuous data streams up to December 2007. The events are shown in two hemispheric presentations: out to $90^{\circ}$ in a linear polar projection centered on the portable array, and from $90^{\circ}$ to $180^{\circ}$ in a comparable projection about the antipole. The figure shows the wide azimuthal and distance coverages of significant seismic events. Using the continuous data sampling available at $100 \mathrm{~Hz}$, we can study the earthquake source process and seismic structure of the Earth by extracting the entire seismic wavefield extending from near-earthquake high-frequency body waves to long-period surface waves. Furthermore, the network provides an unexpected opportunity to record near-antipodal seismic waves from significant seismic events centered in South America (Fig. 5b), with the aim of studying the Earth's deep interior.

Based on continuously collected seismic data, we analyzed the noise level at stations installed during 2005 to evaluate the quality of data for periods ranging from 0.1 to $100 \mathrm{~s}$. For this noise analysis, we selected a large number of 1 -h waveform segments within the available period. For each segment of continuous data, we employed McNamara and Buland's (2004) procedure to estimate the power spectral density (PSD) at each station. Using this approach, we calculated and documented the ambient seismic background noise for direct comparison with standard low- and high-noise models (new low-noise model [NLNM] and new high-noise model [NHNM]; Peterson, 1993).

Table 1 summarizes the analyzed results from vertical components of the broadband high resolution channel (BHZ) of the network. The analysis revealed that the observed ambient noise is strongly dependent on site conditions: stations located on rock sites generally have lower noise levels than those on alluvium sites. Many stations of the Vietnam Seismic Network are located in villages and are operated manually; consequently, a higher level of highfrequency artificial noise (SP) is generally recorded compared with a typical BATS broadband station (SSLB). However, natural and original middle- and long-period (MP and LP) noise at most stations in the Vietnam network occurs at lower levels than that recorded by the Taiwan station SSLB. Noise monitoring for this network is ongoing and is being extended to newly installed stations.

\section{Example of issues arising from recorded array waveforms}

Within the observation period, many seismograms from events at different ranges were recorded with good signal-to-noise $(\mathrm{S} / \mathrm{N})$
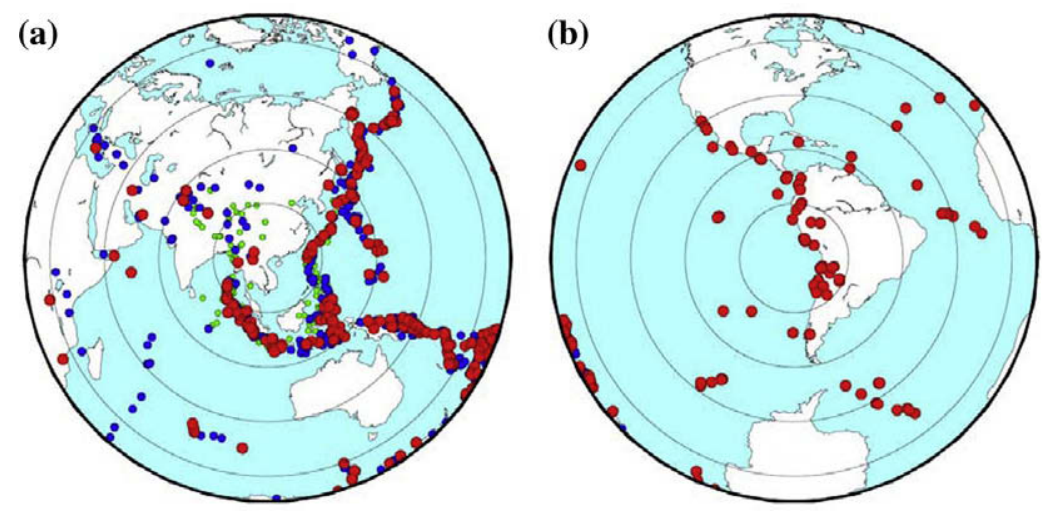

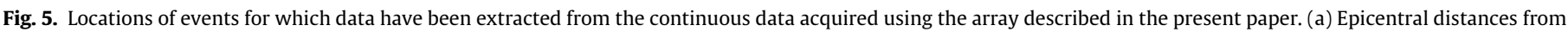

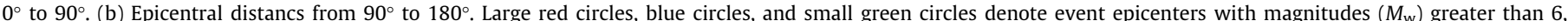

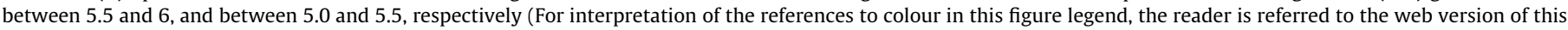
article.). 
Table 1

Magnitude of the broadband high resolution vertical channel (BHZ) noise within stations of the Vietnam Broadband Seismic Network.

\begin{tabular}{lllll}
\hline Station & Sensor & SP $^{\mathrm{a}}$ & $\mathrm{MP}^{\mathrm{b}}$ & $\mathrm{LP}^{\mathrm{c}}$ \\
\hline BGVB & Trillium & $\mathrm{D}^{\mathrm{g}}$ & $\mathrm{B}^{\mathrm{e}}$ & $\mathrm{C}$ \\
DBVB & STS-2 & $\mathrm{E}^{\mathrm{h}}$ & $\mathrm{B}$ & $\mathrm{D}$ \\
DHVB & Trillium & $\mathrm{D}+$ & $\mathrm{B}$ & $\mathrm{C}^{\mathrm{f}}$ \\
DSVB & Trillium & $\mathrm{D}+$ & $\mathrm{B}$ & $\mathrm{C}+$ \\
HBVB & Trillium & $\mathrm{E}$ & $\mathrm{A}^{\mathrm{d}}$ & $\mathrm{B}-$ \\
LAVB & Trillium & $\mathrm{E}$ & $\mathrm{B}$ & $\mathrm{C}$ \\
LCVB & Trillium & $\mathrm{C}$ & $\mathrm{A}$ & $\mathrm{B}-$ \\
MCVB & Trillium & $\mathrm{D}+$ & $\mathrm{A}$ & $\mathrm{B}-$ \\
PLVB & STS-2 & $\mathrm{D}-$ & $\mathrm{C}$ & $\mathrm{C}$ \\
SLVB & Trillium & $\mathrm{C}$ & $\mathrm{A}$ & $\mathrm{B}-$ \\
SPVB & STS-2 & $\mathrm{E}$ & $\mathrm{B}$ & $\mathrm{A}$ \\
TGVB & Trillium & $\mathrm{C}$ & $\mathrm{A}$ & $\mathrm{B}-$ \\
THVB & Trillium & $\mathrm{D}$ & $\mathrm{C}$ & $\mathrm{B}-$ \\
TTVB & Trillium & $\mathrm{C}$ & $\mathrm{A}$ & $\mathrm{B}-$ \\
VIVB & STS-2 & $\mathrm{E}$ & $\mathrm{C}$ & $\mathrm{D}$ \\
SSLB/BATS & STS-2 & $\mathrm{C}$ & $\mathrm{C}$ & $\mathrm{B}$ \\
\hline
\end{tabular}

a $\mathrm{SP}$ indicates noise with a period shorter than $1 \mathrm{~s}$.

b MP indicates noise with a period of 1-10 s.

c $L P$ indicates noise with a period longer than $10 \mathrm{~s}$.

d A: $10 \mathrm{db}>$ Value - NLNM

e $\mathrm{B}: 20 \mathrm{db}>$ Value $-\mathrm{NLNM}>10 \mathrm{~dB}$.

${ }^{f}$ C: $30 \mathrm{db}>$ Value - NLNM $>20 \mathrm{~dB}$.

g D: $40 \mathrm{db}>$ Value $-\mathrm{NLNM}>30 \mathrm{~dB}$.

h E: Value - NLNM > $40 \mathrm{~dB}$.

ratios. Below, we provide several examples of recorded array waveforms to show various types of seismic phases recorded by this array, and present a brief discussion regarding the possible applications of those data.

4.1. Use of local events for estimates of regional stress, crustal structure, and seismic-wave attenuation

The deployed seismic array provides a seismic signal with a wide frequency band and accurate timing; these observations have been used to determine local seismicity. Within the first 2 years of deployment, we located 137 events from our array observations (Fig. 4). Although some of the recorded events are located at the western and northern borders of the array, our observations provide a useful dataset for determining the focal mechanisms of these events by inversion of the broadband seismic waveform (Huang, 1994). As stated in the Introduction, information regarding source mechanisms provides the constraints necessary to verify regional stress when discussing aspects of regional tectonics.

Fig. 6 shows the array waveforms from a single recorded event. The event was well recorded at 24 stations, with epicenter distances ranging from 80 to $500 \mathrm{~km}$ (Fig. 4). Similar local events have been well recorded. Analyses of those records, the accurate crustal structure, thus included velocities and attenuation, can be determined. This may lead to improved estimates of the hypocenter locations and magnitudes of local events in the near future.

4.2. Use of large-magnitude regional shallow events for the analysis of regional crustal structures

During 2007, two large-magnitude shallow events were well recorded by the array (Fig. 7a). One event occurred in Laos on 16 May $\left(M_{\mathrm{w}}=6.3\right)$, and the other in Yunnan, China, on 2 June $\left(M_{\mathrm{w}}=6.2\right)$. Both events were located by the global seismic network with significant uncertainties because of the limited distribution of global seismometers in this region. Observations from the present array provide additional information to constrain the source behaviors and locations of the two events, as well as their aftershocks. Fig. 7b shows the clear crustal phases of recorded array seismograms from the Laos event. These observations may provide useful information in identifying the crustal structure of the region, including any lateral variations. The determined regional structures should prove helpful in improving the earthquake-monitoring and detection capabilities of the network of seismic stations in this region.

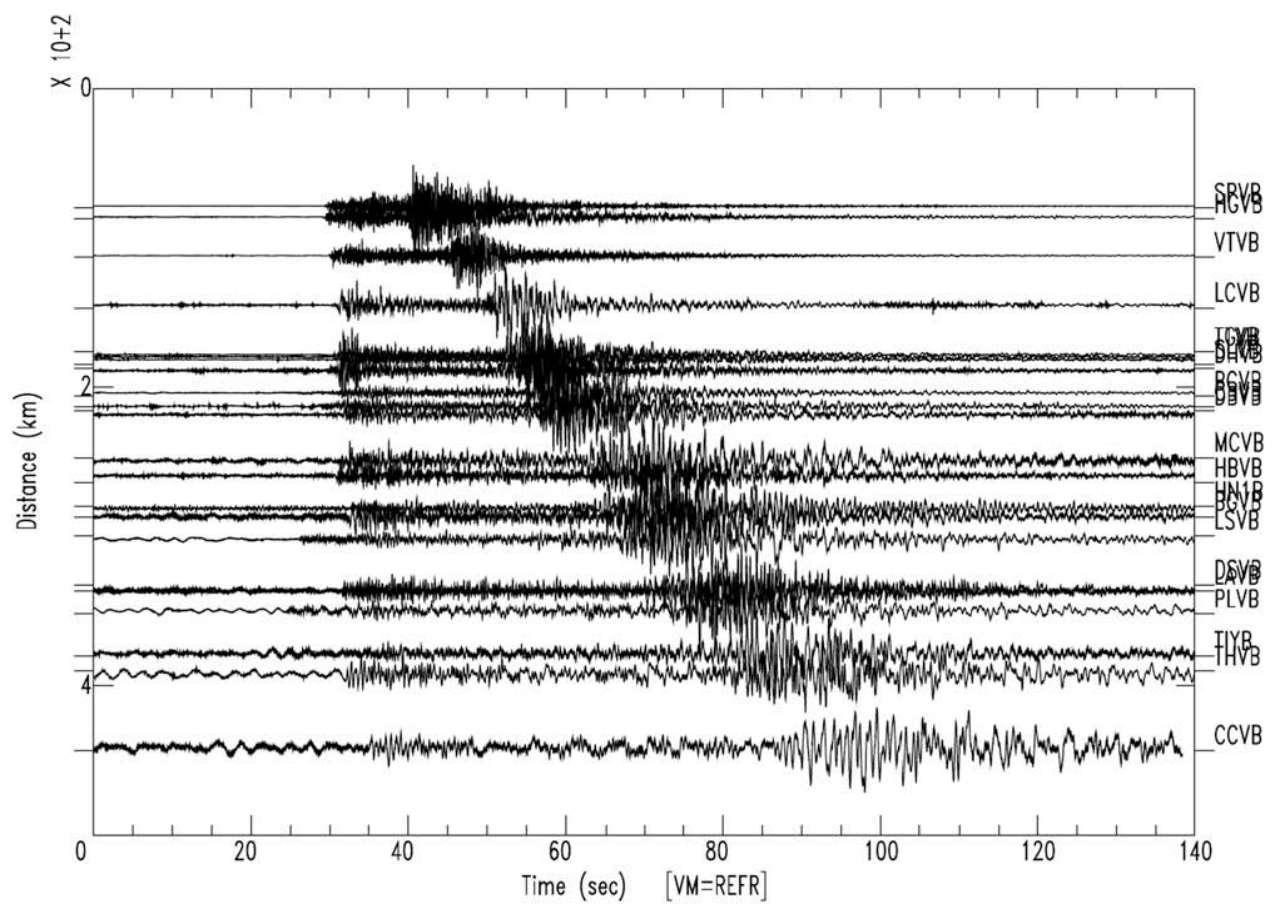

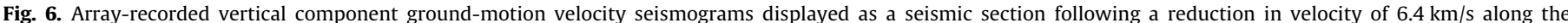

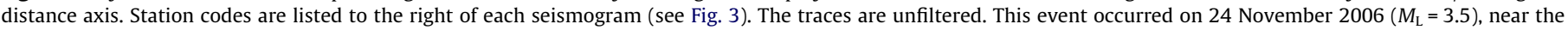
northern margin of the array (indicated by the star in Fig. 4). 
(a)

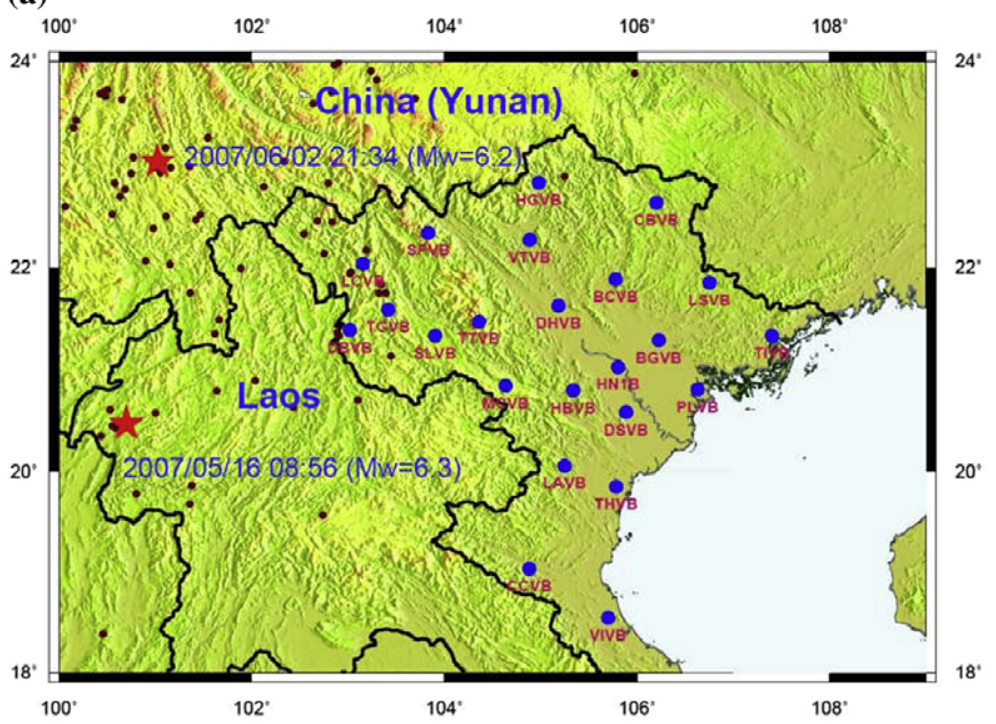

(b)

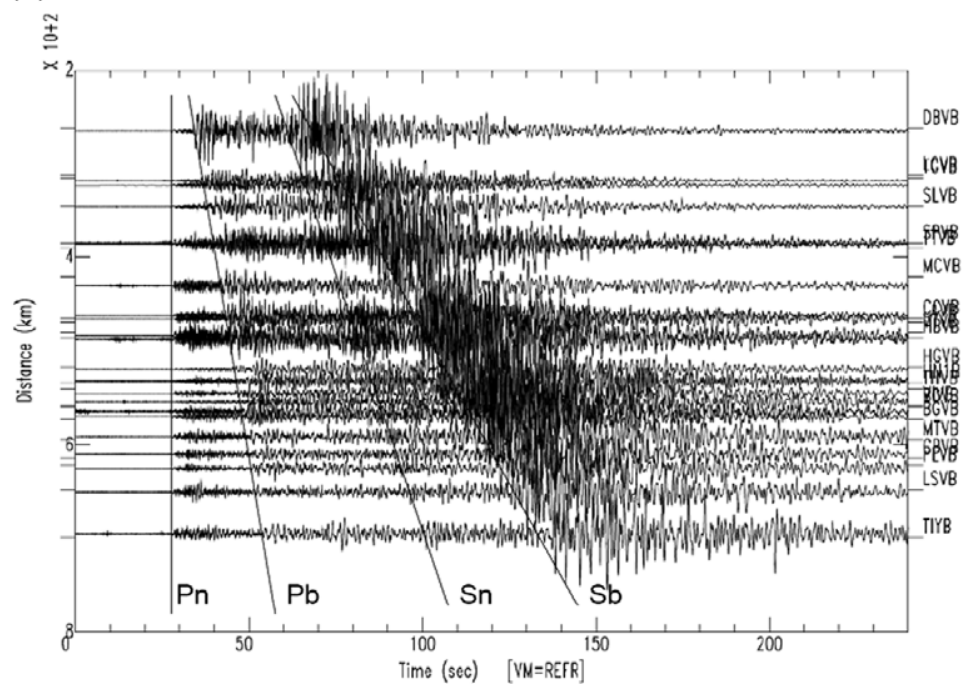

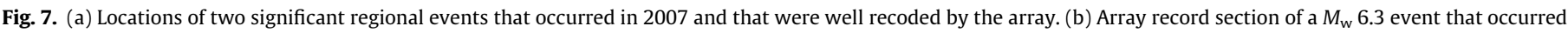

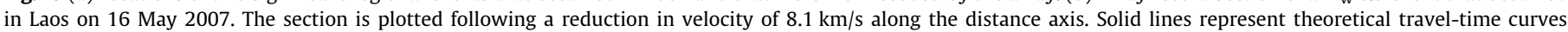

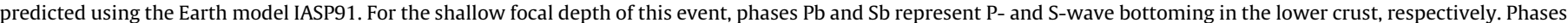
$\mathrm{Pn}$ and $\mathrm{Sn}$ represent P- and S-wave bottoming in the uppermost mantle, respectively.

4.3. Use of teleseismic travel-time residuals for interpreting deep seismic structures beneath the array

The distance between the network in northern Vietnam and zones of large earthquakes is suitable for studying the deep structure beneath the array. Fig. 8a shows a recorded section of P-wave and its later reflection for a $M_{\mathrm{b}} 6.2$ event in the Aleutian Islands at a depth of $117 \mathrm{~km}$. Such array seismograms can be used to determine the relative travel residuals with respect to expected arrival times using, for example, the IASP91 model of Kennett and Engdahl (1991), as indicated in Fig. 8b. The residual pattern shows lateral variations in seismic travel times across the array. A major component of the analysis of data from this array is directed toward delineating the seismic velocities variations in three-dimension for the crust and upper mantle beneath the RRF, using body-wave tomography and teleseismic receiver functions. The results of such studies can be used to image the deep structures of the RRF and to deduce its geodynamic evolution.

\subsection{Use of core phases for studies of the Earth's deep interior}

Vietnam, located at the antipode of the deep seismic zone in South America, is one of a small number of sites where antipodal waveforms are frequently observed. In principle, P-waves travel from their origin through a large area of the Earth's core and focus again at the antipole before being detected on a seismograph. Antipodal seismic data enhance weak phases by a focusing effect. An antipodal earthquake and its nearby events are highly effective in studying waves that have traveled through the center of the Earth's core.

Fig. 9 shows a recorded section of core phases for a $M_{\mathrm{w}} 8.0$ event that occurred in Peru on 15 August 2007, along with a schematic diagram of the ray paths from source to receiver. Poupinet et al. (1993) demonstrated that the details of near-antipodal P-wave trains can be used to constrain the structure of the boundary between the inner and outer core. Observations from array seismograms used to track multiple arrivals across a group of stations 

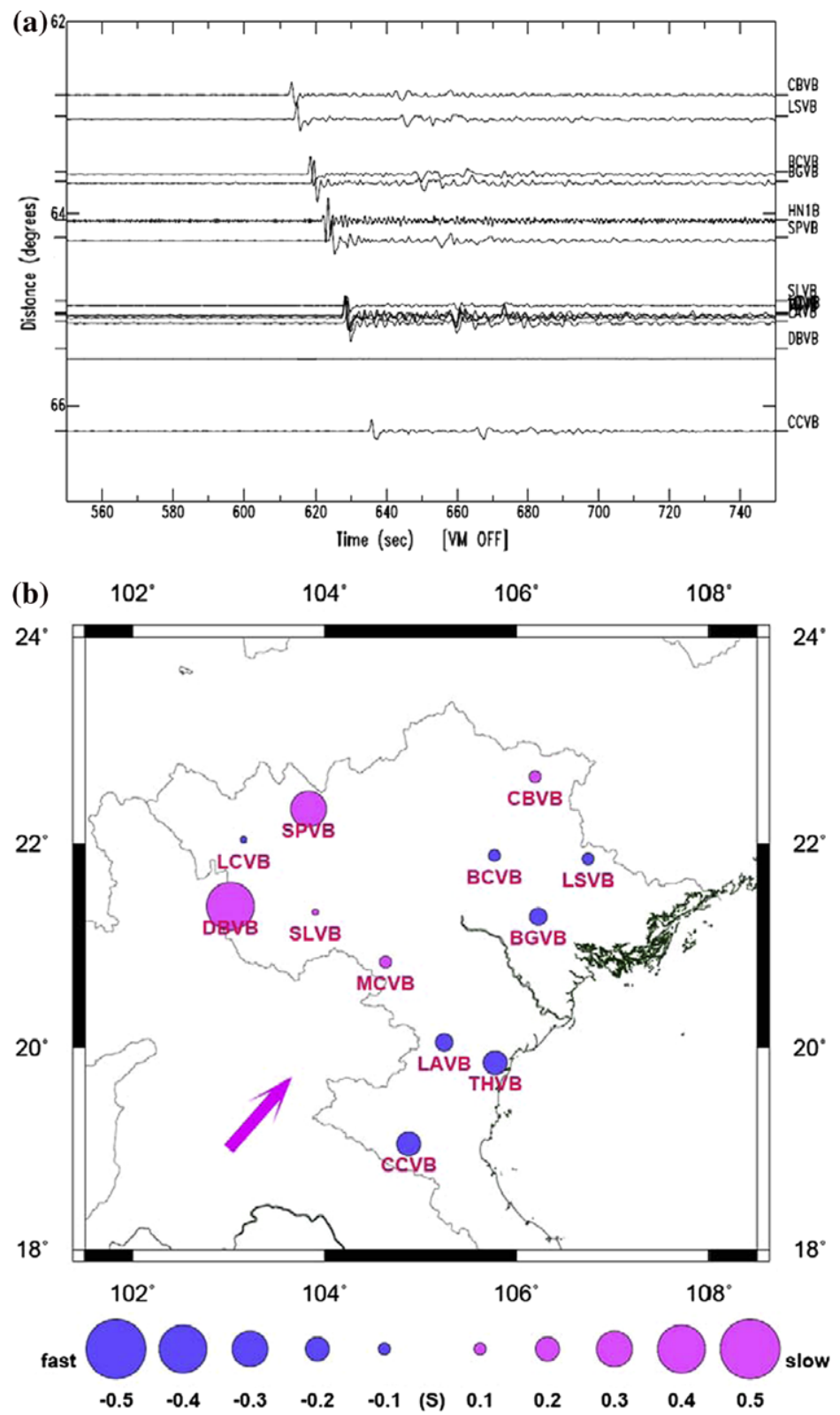

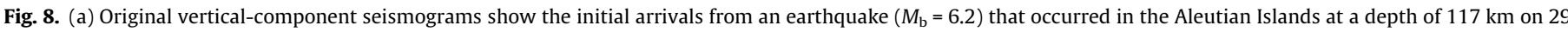

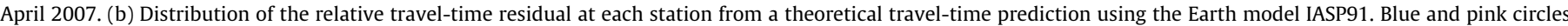

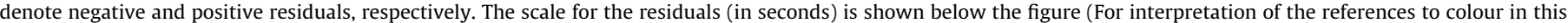
figure legend, the reader is referred to the web version of this article.)

provide significantly more information than can be found from a single record. By comparing information from a number of nearby antipodal sources, we hope to contribute new information regarding the Earth's inner core.

\section{Upgrade of the array to enable real-time earthquake monitoring and early warning}

The Taiwan broadband seismic array deployed in northern Vietnam was originally designed as a field-based observation project. About 2 years of observations are planned; subsequently, the instruments will be distributed throughout the Vietnam region to observe seismic waves with the aim of determining the deep structure of the SCS. Site surveys and station construction are ongoing in central and southern Vietnam. On the second stage of this project, some high-quality stations may be left as permanent stations to contribute to continuous GPS observations. The instruments will be maintained and operated by the Institute of Geophysics (VAST) as part of an international cooperation, and each station will be equipped with a Quanterra Q330 digitizer and PB14F Packet Baler, which will provide the ability to detect local triggering and transmit signals among stations. We are seeking to collaborate with VAST to test and develop this array and to include a real-time function to monitor earthquake activity in the near future. Furthermore, to observe seismic activity ranging from micro-earthquakes to damaging events, it is necessary to install a low-gain acceleration sensor at each station. The project can be considered as a prototype system in constructing a regional broadband seismic 
(a)

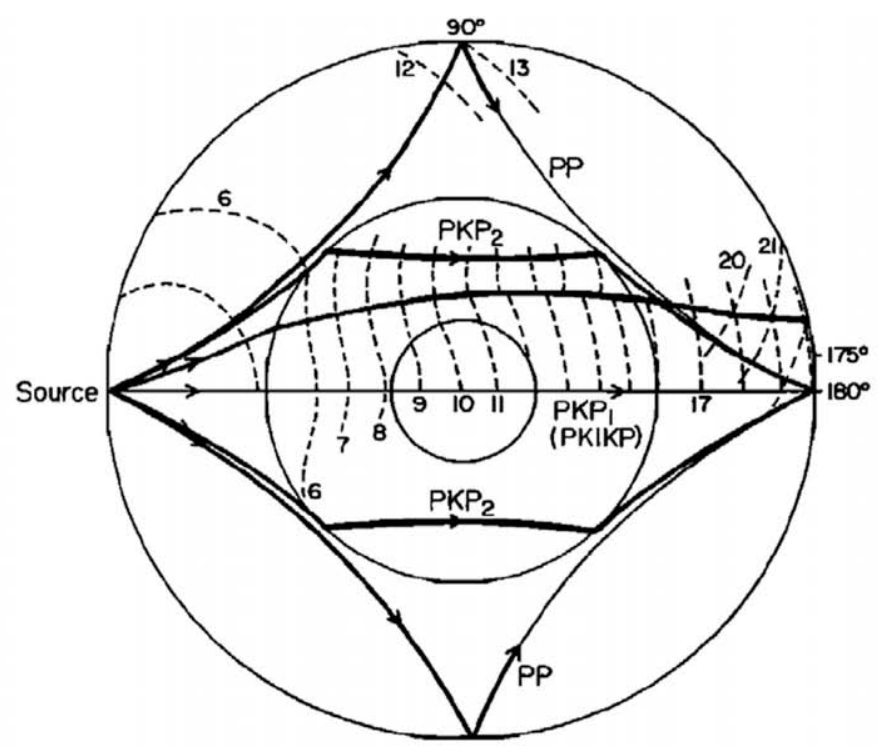

(b)

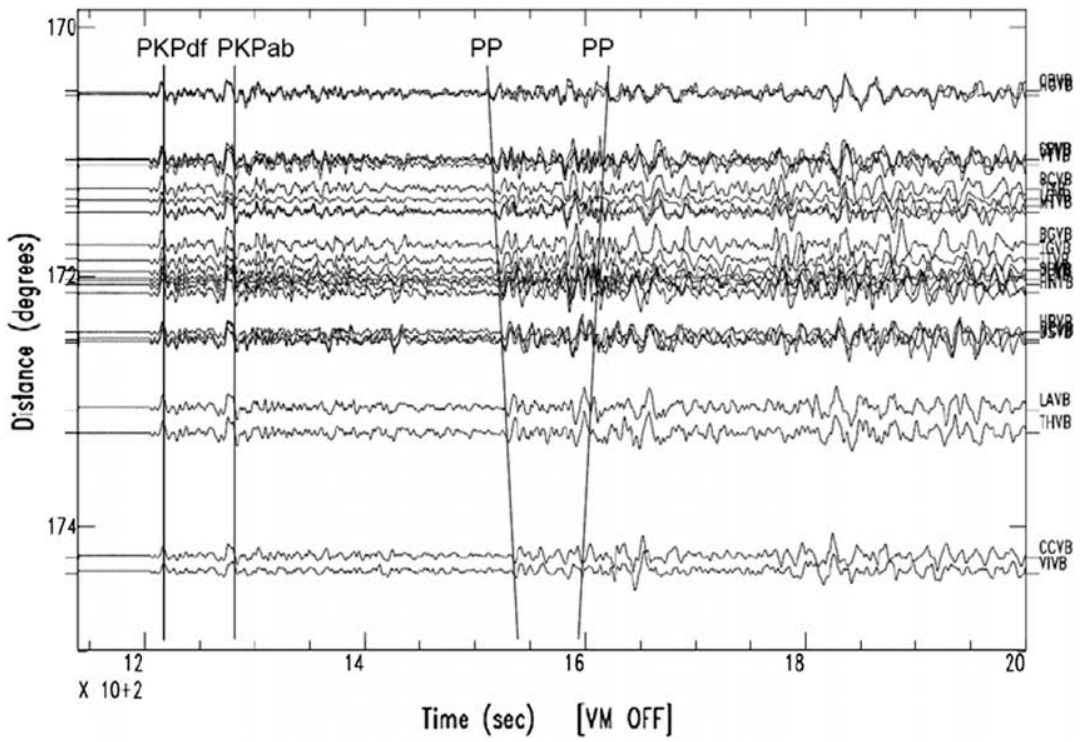

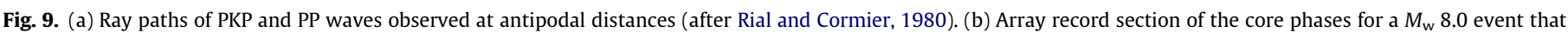

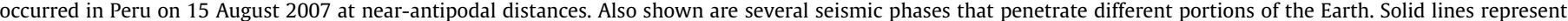
theoretical travel-time curves predicted using the Earth model IASP91.

network; however, the implementation of a modern seismic network involves many different aspects of research and technology related to the development of sophisticated data management and processing, especially as the proposed network is extremely large, extending more than $1600 \mathrm{~km}$ along its long axis. Fortunately, the accumulated experience of IESAS in operating BATS for more than a decade will help to overcome these difficulties.

On 26 December 2006, we were alerted to the danger of earthquake and tsunami hazards along the East China coast arising from the Pingtung earthquakes off southern Taiwan (Liu et al., 2007; Huang et al., 2008; Wu et al., 2008). In the same tectonic province, the Manila Trench is identified as the likely area for future large-magnitude tsunamigenic earthquakes (Kirby et al., 2005; Liu et al., 2009). IESAS is seeking international cooperation to tackle the issue of earthquake and tsunami hazards associated with large earthquakes within the SCS. We plan to contribute several stations to be established in the Philippine is- lands to improve station coverage for earthquake monitoring in the SCS; talks are underway with the Philippine Institute of Volcanology and Seismology (PHIVOLCS). The configuration of the planned network is shown in Fig. 10. The network is designed to monitor large earthquakes in the Manila Trench (labeled PFZ (potential fault zone) in Fig. 10), to provide seismic early-warning information, and to mitigate seismic hazards in both the Philippines and Taiwan. With the integration of existing and planned seismic stations from other agencies in the SCS region (Fig. 10), we hope to establish a suitable system for broadcasting tsunami warnings throughout the SCS area. Recently, BATS was established to construct a satellite-based real-time data transmission system for data collection. This system should prove helpful in constructing a seismic network in the SCS region for the realtime monitoring of earthquakes and tsunamis and the development of an early-warning system jointly operated by countries that border the SCS. 


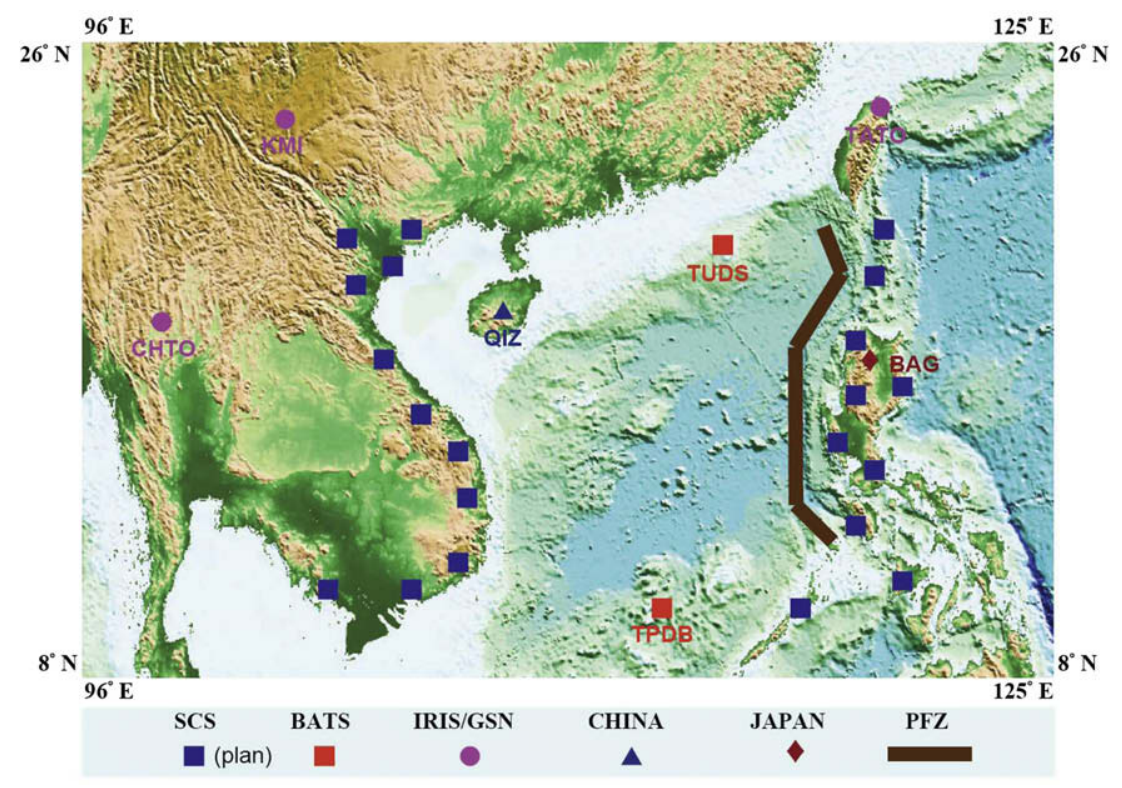

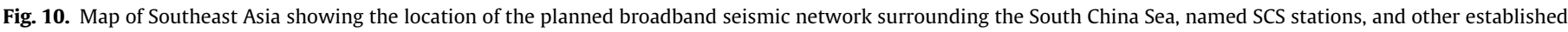

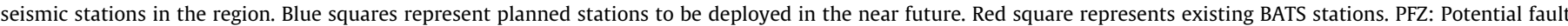

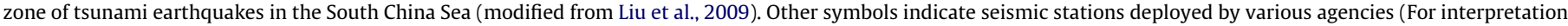
of the references to colour in this figure legend, the reader is referred to the web version of this article.).

\section{Acknowledgements}

We would like to thank the many staff at VAST and IESAS who made this experiment possible. This study was supported by Academia Sinica and the National Science Council, Taiwan, under Grants NSC96-2119-M-001-010 and NSC96-2116-M-001-010.

\section{References}

Chung, S.L., Lee, T.Y., Lo, C.H., Wang, P.L., Chen, C.Y., Nguyen, T.Y., Tran, T.H., Wu, G., 1997. Intraplate extension prior to continental extrusion along the Ailao ShanRed River shear zone. Geology 25, 311-314.

Chung, S.L., Lo, C.H., Lee, T.Y., Zhang, Y., Xie, Y., Li, X., Wang, K.L., Wang, P.L., 1998 Diachronous uplift of the Tibetan plateau starting from 40 Myr ago. Nature 394, 723-725.

Huang, B.S., 1994. Estimation of source parameters by the inversion of near source strong motion wave forms. TAO 5, 11-26.

Huang, B.S., Huang, Y.L., Lee, S.J., Chen, Y.G., Jiang, J.S., 2008. Initial rupture processes of the 2006 Pingtung earthquake from near source strong-motion records. TAO 19, 547-554.

Kao, H., Jian, P.R., Ma, K.F., Huang, B.S., Liu, C.C., 1998. Moment-tensor inversion for offshore earthquakes east of Taiwan and their implications to regional collision. Geophys. Res. Lett. 25, 3619-3622.

Kennett, B.L.N., Engdahl, E.R., 1991. Traveltimes for global earthquake location and phase identification. Geophys. J. Int. 105, 429-465.

Kirby, S., Geist, E., Lee, W.H., Scholl, D., Blakely, R., 2005. Tsunami source characterization for western Pacific subduction zones: a preliminary report. Report, USGS Tsunami Subduction Source Working Group.

Lee, T.Y., Lawver, L.A., 1995. Cenozoic plate reconstruction of Southeast Asia. Tectonophysics 251, 85-138.
Leloup, P.H., Lacassin, R., Tapponnier, R., Zhong, D., Lui, X., 1995. Kinematics of Tertiary left-lateral shearing at the lithosphericscale in the Ailao Shan-Red River shear zone (Yunnan, China). Tectonophysics 251, 3-84.

Liu, P.L.-F., Wang, X., Salisbury A.J., 2009, Tsunami hazard and early warning system in South China Sea, J. Asian Earth Sci., 36 (1), 2-12.

Liu, Y., Angela, S., Shuo, M.W., Yaolin, S., Hailing, L., David, A.Y., 2007. Tsunami hazards along Chinese coast from potential earthquakes in South China Sea. Phys. Earth Planet. Inter. 163, 233-244.

McNamara, D.E., Buland, R.P., 2004. Ambient noise levels in the continental United States. Bull. Seism. Soc. Am. 94, 1517-1527.

Molnar, P., England, P., Martinod, J., 1993. Mantle dynamics, the uplift of the Tibetan Plateau, and the Indian monsoon. Rev. Geophys. 31, 357-396.

Nguyen, D.X., Le, T.S., 2005. Seismic hazard assessment for Vietnam Territory In: Proceeding of the 4th Conference of Vietnamese Association of Geophysics, Publishing House of Science and Technology, Hanoi, Vietnam, pp. 281-304.

Peterson, J., 1993. Observation and modeling of seismic background noise, US Geol. Surv. Tech. Rept., 93-322, 94p.

Poupinet, G., Souriau, A., Jenatton, L., 1993. A test on the Earth's core-mantle boundary structure with antipodal data: example of Fiji-Tonga earthquakes recorded in Tamanrasset, Algeria. Geophys. J. Int. 113, 684-692.

Rial, J.A., Cormier, V.F., 1980. Seismic waves at the epicenter's antipode. J. Geophys. Res. 85, 2661-2668.

Tapponnier, P., Peltzer, G., Armijo, R., 1986. On the mechanics of the collision between India and Asia. In: Coward, M.P., Ries, A.C. (Eds.), Collision Tectonics, vol. 19. Geol. Soc. Lond. Spec. Publ., pp. 115-157.

Tapponnier, P.G., Lacassin, R., Leloup, P.H., Schärer, U., Zhong, D., Wu, H., Liu, X., Ji, S. Zhang, L., Zhong, J., 1990. The Ailao Shan/Red River metamorphic belt: tertiary left-lateral shear between Indochina and South China. Nature 343, 431-437.

Wu, T.R., Chen, P.F., Tsai, W.T., Chen, G.Y., 2008. Numerical study on tsunamis excited by 2006 Pingtung Earthquake Doublet. TAO 19, 705-715. 